\title{
eHealth adoption and use among healthcare professionals in a tertiary hospital in Sub-Saharan Africa: A Qmethodology study
}

\author{
Muhammad Awwal Ladan ${ }^{\text {Corresp.. }}{ }^{1}$, Heather Wharrad ${ }^{1}$, Richard Windle ${ }^{1}$ \\ ${ }^{1}$ Digital Innovations in Education and Healthcare (DICE), School of Health Sciences, University of Nottingham, Nottingham, United Kingdom \\ Corresponding Author: Muhammad Awwal Ladan \\ Email address: muhammad.ladan@nottingham.ac.uk
}

Background : The aim of the study was to explore the viewpoints of healthcare professionals (HCPs) on the adoption and use of eHealth in clinical practice in sub-Saharan Africa (SSA). Information and communication technologies (ICTS) including eHealth provide HCPs the opportunity to provide quality healthcare to their patients while also improving their own clinical practices. Despite this, previous research has identified these technologies have their associated challenges when adopting them for clinical practice. But more research is needed to identify how these eHealth resources influence clinical practice. In addition, there is still little information about adoption and use of these technologies by HCPs inclinical practice in Sub-Saharan Africa.

Method : An exploratory descriptive design was adopted for this study. Thirty-six (36) HCPs (18 nurses and 18 physicians) working in the clinical area in a tertiary health institution in SSA participated in this study. Using Qmethodology, study participants rank-ordered forty-six statementsin relation to their adoption and use of eHealth within their clinical practice. This was analysed using by-person factor analysis and complemented with audio-taped interviews.

Results : The analysis yielded four factors i.e.distinct viewpoints the HCPs hold about adoption and use of eHealth within their clinical practice. These factors include: "Patient-focused eHealth advocates" who use the eHealth because they are motivated by patients and their families preferences; "Task-focused eHealth advocates" use eHealth because it helps them complete clinical tasks; "Traditionalisticpragmatists" recognise contributions eHealth makes in clinical practice but separate from their routine clinical activities; and the "Tech-focused eHealth advocates" who use the eHealth because they are motivated by the technology itself.

Conclusion : The study shows the equivocal viewpoints that HCPs have about eHealth within their clinical practice. This, in addition to adding to existing literature, will help policymakers/decision makers to consider HCPs views about these technologies prior to implementing an eHealth resource. 


\section{1 eHealth adoption and use among healthcare}

2 professionals in a tertiary hospital in Sub-Saharan

3 Africa: A Qmethodology study

Muhammad Awwal Ladan ${ }^{1}$, Heather Wharrad ${ }^{1}$, Richard Windle ${ }^{1}$

6

${ }^{1}$ Digital Innovations in Healthcare and Education (DICE), School of Health Sciences, University of Nottingham, Nottingham, UK

10 Corresponding Author:

11 Muhammad Awwal Ladan ${ }^{1}$

12 School of Health Sciences, University of Nottingham, Nottingham, NG7 2HA, UK

13 Email address: Muhammad.Ladan@nottingham.ac.uk; maladanfab@gmail.com 14 

professionals in a tertiary hospital in Sub-Saharan Africa: A Qmethodology study

Muhammad Awwal Ladan ${ }^{1}$, Heather Wharrad ${ }^{1}$, Richard Windle ${ }^{1}$

21

${ }^{1}$ Digital Innovations in Healthcare and Education (DICE), School of Health Sciences, University of Nottingham, Nottingham,UK

Corresponding Author:

Muhammad Awwal Ladan ${ }^{1}$

27

School of Health Sciences, University of Nottingham, Nottingham, NG7 2HA, UK

Email address: Muhammad.Ladan@nottingham.ac.uk; maladanfab@gmail.com

\section{ABSTRACT}

Background: The aim of the study was to explore the viewpoints of healthcare professionals (HCPs) on the adoption and use of eHealth in clinical practice in sub-Saharan Africa (SSA). Information and communication technologies (ICTs) including eHealth provide HCPs the opportunity to provide quality healthcare to their patients while also improving their own clinical practices. Despite this, previous research has identified these technologies have their associated challenges when adopting them for clinical practice. But more research is needed to identify how these eHealth resources influence clinical practice. In addition, there is still little information about adoption and use of these technologies by HCPs in clinical practice in Sub-Saharan Africa. Method: An exploratory descriptive design was adopted for this study. Thirty-six (36) HCPs (18 nurses and 18 physicians) working in the clinical area in a tertiary health institution in SSA participated in this study. Using Qmethodology, study participants rank-ordered forty-six statements in relation to their adoption and use of eHealth within their clinical practice. This was analysed using by-person factor analysis and complemented with audio-taped interviews.

Results: The analysis yielded four factors i.e. distinct viewpoints the HCPs hold about adoption and use of eHealth within their clinical practice. These factors include: "Patient-focused eHealth advocates" who use the eHealth because they are motivated by patients and their families preferences; "Task-focused eHealth advocates" use eHealth because it helps them complete clinical tasks; "Traditionalistic-pragmatists" recognise contributions eHealth makes in clinical practice but separate from their routine clinical activities; and the "Tech-focused eHealth advocates" who use the eHealth because they are motivated by the technology itself. their clinical practice. This in addition to adding to existing literature, will help 
53 policymakers/decision makers to consider HCPs views about these technologies prior to

54 implementing an eHealth resource.

\section{INTRODUCTION}

56 Information and communication technologies (ICTs) have been identified to have the potential to

57 address many of the challenges that many of the healthcare systems are currently confronting,

58 such as improving information management, access to health services, quality and safety of care

59 and cost containment and the request by patients that clinicians should use ICTs. Thus with

60 increase computerisation in every sector of activity, ICTs are expected to become resources that

61 are part of healthcare professional (HCP) practice (Gagnon et al. 2012). Buntin et al. (2011)

62 argues that though some HCPs may choose to function without healthcare technologies, these

63 technologies has the potential to improve health of individuals' including the performance of the

64 HCPs. They further state that the technologies will yield improved quality of the service

65 provision, cost saving including greater patient engagement with their own care. eHealth is

66 defined as "the promotion, empowering and facilitating health and wellbeing with individual,

67 families and communities and the enhancement of professional practice using information

68

69

70

71

72

73

74

75

76

77

78

79

80

81

82

83

84

85

86

87

88

89

90

91

92

management and information and communication technologies" (RCN 2017). However, within this study eHealth resources will be delimited to the internet, internet enabled desktop computers available within the hospital wards, mobile devices, and electronic health records (EHR).

Despite the importance of eHealth, some healthcare services do not adopt new ICT therefore risking inefficiencies in the provision of quality healthcare and loss of credibility among their patients (Barello et al. 2015; Koivunen et al. 2008; Ruland \& Bakken 2001; Zayyad \& Toycan 2018). HCPs are in the best position to identify the barriers and facilitators they face in their work environment that could be improved by ICT. However, some HCPs including physicians have been identified to lag behind in the adoption of eHealth (Gagnon et al. 2014; Phichitchaisopa \& Naenna 2013). But Lupiáñez-Villanueva et al. (2011) have reported that other HCPs such as nurses, incorporate eHealth into their practice at a rate significantly lower than physicians.

There have been attempts by different researchers to identify different facilitators and barriers to eHealth use in healthcare. As described by Gagnon et al. (2012), factors facilitating adoption may be geared towards specific perceptions about the characteristics of the eHealth resources by HCPs'. Barriers to adoption may also involve such characteristics but could also include individual, professionals and organisational factors. Verhoeven et al. (2009) identified four categories of factors that might influence eHealth adoption and use among healthcare workers. These include; technological factors, individual factors, work related factors; and organisational factors.

Akanbi et al. (2012) reviewed the progress and challenges of EHR use in sub-Saharan Africa (SSA). They reported that issues such as improved access to the internet, increased use of personal computers, and collaborations between health institutions and international partners have increased the use of ICT within healthcare practice. However, they identified that such reported use are often obtained from HIV/AIDS collaborative care centres which might have 
93 resulted in little or no information on its broader application within existing literature as reported

94 by Gagnon et al. (2012). Furthermore, Akanbi et al. (2012) suggested that exorbitant cost of 95 software and parallel data entry among challenges they identified affecting the use of ICT in 96 clinical practice. Other barriers to the adoption of these eHealth resources were identified as: 97 poor existing infrastructure, frequent power outages, network failure, and lack of comfort with 98 EHR among healthcare workers as a human factor (Akanbi et al. 2012). They concluded that 99 government healthcare institutions are notably slow in adopting such eHealth resources to

100

101

102

103

104

105

106

107

108

109

110

111

112

113

114

115

116

117

118

119

120

121

122

123

124

125

126

127

128

129

130

131

132 improve healthcare. In line with this, Ami-Narh \& Williams (2012) suggested that for a successful eHealth adoption by HCPs in clinical practice, the commitment of stakeholders should be considered and understood. They argue that this will address the little attention that eHealth decisions in Africa has received. In addition, Zayyad \& Toycan (2018) identified that the level of eHealth adoption by healthcare institutions in Nigeria is generally poor. They attributed this to poor infrastructure and a lack policies that guide eHealth adoption within the country. Similarly, Zayyad \& Toycan (2018) like previous studies (Akanbi et al. 2012; Ami-Narh \& Williams 2012; Gagnon et al. 2012) identified certain barriers to eHealth adoption in Nigeria such as infrastructure barriers, technology literacy barriers, funding barriers, human resource barriers, administrative and security barriers.

Certain factors that affect adoption and use of these eHealth resources have been identified by Gagnon et al. (2012) as human and organisational factors. They identified that some of these factors alternate between facilitators and barriers. These include: factors related to ICT [perception of benefits of the innovation, ease of use, compatibility with work process, interoperability, validity of the resources, etc.], Individual and professional factors [lack of familiarity with ICT], Human environment [patient/health professional interaction, applicability to patients' characteristics and attitude of colleagues towards ICT and, patient attitude regarding ICT] and, Organisational environment [IT support, training, access to ICT, organisational support, etc.]. This interchange between barriers and facilitators might be due to participants' personal views on which factor is identified as a barrier or not, thus uncovering their respective subjectivities in defining each factor. In the same way, Terry et al. (2009) identified factors such as computer literacy, training, time in using the tool, the presence of "in-house" problem solvers and also an integrated message system with the eHealth resource could serve as barriers or facilitators. Other notable barriers that have also been highlighted by Gagnon et al. (2014) include human factors such as resistance to change due to fear of being replaced by a new technology or by someone with better ICT skills. They also report that if HCPs do not perceive any added value of ICT use in their routine activities they are likely to resist it.

The setting for this study is one of the oldest and largest teaching hospitals in Nigeria. At creation, the institution had the objective of providing facilities for training of doctors, nurses and other health personal. Presently the control of the hospital is by the Federal government of Nigeria supervised by the Ministry of Health. The hospital at the time of this study had 750 beds with 622 physicians and 800 nurses. The hospital has 21 clinical departments including pharmacy and physiotherapy. In November 2005, the hospital moved to its permanent site, which 
133 was a much larger and more equipped health facility with internet enabled desktops in each

134 clinical ward for documentation of clinical activities including patient health records. As at 2016,

135 all desktops within the clinical wards were withdrawn and replaced with one hundred Z-pads (a

136 mobile hand-held device) though no software has been incorporated within the hand-held

137 devices. Furthermore, the management of the area of study has at various stages attempted to

138 provide an enabling eHealth environment for the HCP's to function. However, despite huge

139 investments in both time and finance, there has been continuous reports of both non-use or

140 abandonment of the available technologies.

141 Thus, what is needed to uncover the complex interplay of factors acting as barriers for some or

142 facilitators for others is a new methodology to separate out these viewpoints. It is perceived that

143 HCPs exposed to these technologies will have their own understanding of the applicable eHealth

144 tool. These understandings/beliefs regarding an ICT platform/solution or application have a

145 direct impact on the individual or group behavioural intentions or actual use of such

146 technologies. These understandings, beliefs, or views could be individual specific,

147 group/speciality specific or inter-group/inter-speciality specific. As a consequence of these

148 views, attitudes as well as perceptions maybe modified by key indicators such as individual

149 differences, system characteristics, social influence, and facilitating conditions (Venkatesh \&

150 Bala 2008).

151 The subjective domain of the individual or group generate views, opinions, beliefs, attitudes, as

152 well as perceptions. This subjectivity presents the individuals' unique stand on an issue. Akhtar-

153 Danesh et al. (2008) defines subjectivity as judgment based on individual personal impressions,

154 feelings and opinions rather than external facts. Stephenson (1986) reported that in the subjective

155 domain, only the individual concerned can observe and measure (order, position) his/her

156 subjectivity. He further stated for this reason that the research approach called Q methodology is

157 so significant, as a closed system for making subjective measurements. In this regard, Q

158 methodology was adopted a methodological approach to explore the HCPs adoption and use of

159 eHealth within their clinical practice. This mixed-method approach (Ramlo 2015; Ramlo \&

160 Newman 2011) is expected to provide an understanding of end-users views. In addition, Ami-

161 Narh \& Williams (2012) emphasised the use of mixed-method approaches to eHealth research

162 among HCPs in order to avoid blindly adhering to the labels of quantitative or qualitative

163 paradigms. This will favourably affect decisions by the both end-users (HCPs) themselves and

164 those responsible for decisions on eHealth policies (Ami-Narh \& Williams 2012).

165 The aim of the study was to explore viewpoints of HCPs on adoption and use of eHealth in

166 clinical practice in sub-Saharan Africa.

167 MATERIALS \& METHODS

168 Qmethodology was developed by William Stephenson in the 1930's as a way to scientifically

169 measure human subjectivity (Ho 2017). The methodology combines a mix of both qualitative

170 and quantitative techniques which allows subjective viewpoints of persons to be revealed in a

171 holistic fashion (Stenner et al. 2000; Watts et al. 2018). The methodology relies on an in-depth

172 collection of statement items (vanExel \& Graaf 2005; Webler et al. 2009) on a topic which are 
173 then provided to participants to rank order based on their agreement or disagreement as it relates

174 to them (Ladan et al. 2018). This is then subjected to a by-person factor analysis to produce a

175 gestalt expression (Watts \& Stenner 2005) of the participants' viewpoints on the subject. The

176 methodology rests on the constructivist paradigm (Ramlo 2015; Ramlo \& Newman 2011;

177 Stenner 2009) which sees participants actively making meaning to identify what is important,

178 viewed, or attended (Watts \& Stenner 2012).

179 The sample statements for this study was developed from literature on the models of acceptance

180 and use. It also included literature on factors influencing eHealth adoption within clinical

181 practice and interviews with eHealth experts within the host institution and Nottingham

182 University Hospitals NHS Trust. The process of development of the statements and validation

183 has been presented elsewhere by Ladan et al. (2018).

184 Design

185 An exploratory descriptive design was adopted for this study.

186 Sample

187 In July 2016, 36 HCPs were recruited from the host tertiary health institution in Nigeria, SSA to 188 participate in this study. The hospital at the time of this study had 750 beds with 622 physicians 189 and 800 nurses. Anecdotal evidence which was subsequently supported by the findings of this 190 study suggested that the management of the hospital have unsuccessfully attempted to provide 191 eHealth resources to HCPs in the clinical area. Thirty-six (36) participants or P-set (18 nurses 192 and 18 physicians) were recruited for participation in this study. These participants were 193 purposively selected based on their experience in using eHealth and their understanding of how 194 these eHealth resources influence their respective clinical practices and also in line with the Q195 methodology process (Brown 1980; Ho 2017; Zabala \& Pascual 2016). As suggested by Brown 196 (2010), a P-matrix was adopted to inform the final selection of participants. The P-matrix (Table

197 1) characteristics include; age, gender, years of experience, and profession. This yielded a matrix 198 of: 2 [gender] x 3 [age] x 3 [years of experience] x 2 [profession]. These socio-demographic 199 characteristics seen in Table 2 contributed to the final participant estimate (Paige \& Morin 2015). 200 The inclusion criteria involved all HCPs working in the clinical area that use or have used any of 201 the eHealth facilities (internet enabled desktops and mobile devices within the wards or 202 consulting rooms) provided by the hospital management. HCPs that have not used eHealth 203 facilities provided by the hospital management were excluded from participation, this this also 204 includes HCPs engaged only in academic duties.

\section{Ethical considerations}

206 Ethical approval for this study was obtained from both the Faculty of Medicine and Health 207 Sciences (FMHS) ethics committee in the host institution and the study site in March 2016 and 208 June 2016 (H16022016SoHS and ABUTHZ/HREC/V10/2016) respectively. All data collected 209 has been anonymised. All participants were informed that both their sorting exercise and audio 210 interviews will only be available to the research team. Consent forms were completed in 211 duplicates with the participants keeping a copy for their records while the researcher retained the 212 other copy. In relation to data protection, this was in line with the guidelines of the host 
213 institution research with human subjects. All study records are kept under the responsibility of

214 HW in a securely archived facility.

215 Data collection

216 Traditionally, data collection in Q-methodology involves participants to rank-order a set of

217 statements. This ranking or sorting is based on their interpretation of how they agree or disagree

218 with the statements along a researcher provided grid (Ho 2017; Ladan et al. 2018). In this study,

219 forty-six statements were provided to each HCP participant to rank-order along a 13-scale (-6 to

$220+6$ ) sorting grid printed on an A0 poster (Figure 1).

221 These statements or Q-set were developed from a rigorous pilot study which has been described

222 in detail elsewhere (Ladan et al. 2018). All Q-sets were printed on laminated cards and each

223 participant rank-ordered them along the sorting grid based on their individual interpretation of

224 the statements as it affects them. A completed ranked statement is the called a Qsort. After each

225 sorting exercise, the Qsorts were copied into an A4-sized duplicate of the sorting grid. The

226 participants were then interviewed to discuss their finished Qsort. This interview was audio-

227 taped and subsequently transcribed for analysis.

228 Data analysis

229 The PQMethod version 2.35 developed by Peter Schmolck (Schmolck 2014) for Q-methodology 230 analysis was used for analysis while Ken-Q analysis software (February 2017 version) was used

231 to validate the results of the former software. Both versions of the software were freely available

232 online during data analysis. After data collection, all completed Qsorts by participants were

233 entered in the PQMethod. An inter-correlation of all thirty-six Qsorts was done which was

234 followed by a Centroid factor extraction and Varimax rotation to identify the best factor solution.

235 This resulted in a four-factor solution with an explained variance of 51\%. These Factors

236 (participants shared viewpoints) were interpreted using both factor arrays (Table 3) and crib

237 sheets (Appendix A) (Watts \& Stenner 2012). The Factor arrays and crib sheet use the weighted

238 average of all the Q-sort loadings and the ranking of a statement within a Factor in relation to

239 another Factor respectively. This interpretation is a hermeneutic process which involves a

240 holistic narrative presentation of the factor array (Stenner et al. 2000). In this study, like other Q-

241 methodology studies (Petit dit Dariel et al. 2013; Watts \& Stenner 2005) this narrative was

242 complemented by the post sort interviews in the construction of Factor narratives.

\section{RESULTS}

244 The data analysis yielded four distinct Factors of HCPs about what influences their adoption and 245 use of eHealth within their clinical practice in SSA.

246 The four Factors that emerged are seen in Table 4. It should be noted that while interpreting a

247 Factor, the statement number and its corresponding rank as they appear within the factor array

248 are represented in a bracket. For example, $(\mathbf{3 6}, \mathbf{- 1})$ means statement 36 is ranked at -1 along the

249 sorting grid $(-6$ to +6$)$ within the Factor interpreted. This helps in the hermeneutic interpretation

250 process which provides a holistic narrative as it shows how statements are linked within a Factor.

251 It is important to also note that like in standard factor analysis, eigenvalues in excess of 1.00

252 contribute to the selection of Factors (Brown 1980; Watts \& Stenner 2005; Watts \& Stenner 
253

254

255

256

257

258

259

260

261

262

263

264

265

266

267

268

269

270

271

272

273

274

275

276

277

278

279

280

281

282

283

284

285

286

287

288

289

290

291

292

2012) in Q-methodology. These are the are calculated by summing the square loadings of all the sorts within a factor (Watts \& Stenner 2012).

\section{Factor 1: Patient-focused eHealth advocates}

Factor 1 has seven significantly loading participants and explains $13 \%$ of the study variance. It has an eigenvalue of 4.68. Five of the loading participants are physicians and two are nurses. There are two females and five males with an average age of 37.7 years. HCPs within this Factor recognise that eHealth improves their work efficiency $(33,+5)$ without the influence of their personal characteristics such as age and gender $(24,+5 ; 40,-5)$ or their previous ICT experience $(36,-1)$. They consider the views of their patients/families when using these technologies $(35,+1 ; 15,+2)$ and will continue using it if it is made available beyond their departments $(5,+6)$. Even though they identify that it is not easy to become used to these technologies as well as remembering how to perform tasks using it $(26,+1 ; 16,-2 ; 1,+2)$, it still helps them in accomplishing tasks more quickly $(39,+3)$. Diminished support from both management and superiors $(28,-6 ; 11,-5 ; 4,-1 ; 37,+2)$ led to the provision of eHealth resources which are rather challenging to adopt and use $(22,-3 ; 38,-4)$. HCPs have concerns when it comes to accessing such technologies $(25,-3)$ and this affects their confidence when applying these technologies within their clinical practice $(43,0 ; 31,0)$. For them, issues such as compatibility with other technology platforms $(46,-1)$ play a role in adopting such technologies to simplify their daily routines in the clinical setting.

\section{Factor 2: Task-focused eHealth advocates}

Factor 2 has seven significantly loading participants and explains $13 \%$ of the study variance. It has an eigenvalue of 4.68. Five of the loading participants are physicians and two are nurses. There are two females and five males within this Factor with an average age of 42.6 years. Though HCPs within this Factor show high value of eHealth resources within their clinical practice $(9,+6 ; 33,+4 ; 5,+1)$, as well as confidence in using it $(13,-5 ; 43,-5 ; 31,0)$, they still put a lot of mental effort to get used to it despite having ICT experience $(17,-4 ; 36,+3)$. Accordingly, they use these technologies specifically for the tasks they want to perform $(45,+2)$ and without interruption to their routine activities $(30,-3)$. However, HCPs within this Factor still have concerns with the reliability of these technologies $(8,-3)$. Despite considering the patients/families views as contributors to their own choice to use the eHealth resources $(42,+1)$, eHealth resources contribution to their tasks/activities are the main motivators to their use $(7,+5$; $6,+4 ; 2,+5 ; 3,+2)$. In spite of the management not organising regular training for the use of eHealth resources within the hospital $(28,-3)$, they have been helpful unlike clinical superiors $(4,-2)$ in the provision of voluntary, clear and understandable eHealth $(23,0 ; 19,+2 ; 38,+1 ; 22$, $+3 ; 32,-1)$. Use of the eHealth resources by the participants in this Factor are not influenced by their gender $(40,-5)$ or desire to be different from other HCPs $(14,-6)$.

\section{Factor 3: Traditionalistic-pragmatists}

Factor 3 has six significantly loading participants and explains $10 \%$ of the study variance. It has an eigenvalue of 3.6. Three of the participants are nurses and three are physicians. There are three females and three males within this Factor and they have an average age of 42.8 years. 
293 Having identified that their use of clinical ICT resources as voluntary and within their control $294(23,+6 ; 25,+2)$, HCPs within this Factor indicate that the available eHealth resources enable 295 them to accomplish their clinical tasks quickly, make caring for patients easier and improves 296 their work out put $(39,+5,6,+4 ; 10,+1 ; 34,+2 ; 7,+2 ; 2,+1)$ even though its use interferes with 297 other routine clinical activities $(30,+5)$. Although the HCPs have some confidence in the use of 298 the eHealth technologies $(31,+3 ; 34,+2 ; 8,+3)$ they are still hesitant in the use of it $(13,-1 ; 44,-$ 299 4; 3, -2). Moreover, participants within this Factor can continue carrying out their clinical

300

301

302

303

304

305

306

307

308

309

310

311

312

313

314

315

316

317

318

319

320

321

322

323

324

325

326

327

328

329

330

331

responsibilities without the eHealth resources $(18,-4)$ because it is not specific to their routine tasks $(45,-2 ; 21,0)$ and remembering how to use it is also challenging $(1,0)$. Patients/families views are not considered to be determinants for the uptake of such technologies by these HCPs $(42,-3 ; 35,-5 ; 15,-5)$. This is despite other people that are not even related to their clinical practice motivating them to use the technologies within their work $(41,+1)$. HCPs also do not see the use of the eHealth resources as making them unique from their colleagues or even giving them the opportunity to be recognised for their efforts $(14,0 ; 20,-4 ; 12,-5)$. This is aggravated by the poor support from the management and clinical superiors $(11,-1 ; 28,-3 ; 32,-1 ; 4,-2)$.

\section{Factor 4: Tech-focused eHealth advocates}

Factor 4 has eight significantly loading participants and explains $15 \%$ of the study variance. It has an eigenvalue of 5.4. Five of the participants are nurses and three are physicians. There are four females and four males within this Factor and they have an average age of 44.9 years.

Participants within this Factor acknowledge the importance of the eHealth within their clinical practice $(29,+6)$. They recognise that the use of the eHealth is crucial to their individual clinical practices $(33,+5 ; 21,+2 ; 39,+5 ; 6,+1 ; 3,+2 ; 30,-3)$ and even look for opportunities to use it $(27,+5)$ irrespective of their gender $(40,-5)$. This is because they find these technologies not difficult to become used to $(26,+4 ; 1,+2 ; 17,0 ; 16,+3)$ though they must overcome compatibility issues $(46,-4 ; 34,-2)$. Despite this however, they do not strongly rely on it for their clinical decisions $(9,0)$ because there is less routine update of the eHealth $(44,+1)$ and this hinders their adoption and use of it in areas of the hospital where it is lacking $(18,+4 ; 38,-4)$. This is also made more challenging by the non-availability of management and technical support including support from both colleagues within and outside the clinical environment $(19,-6 ; 4,-2$; $37,-2 ; 41,-2)$. Moreover, HCPs recognise that using eHealth in clinical practice does not accrue to them any professional developmental advantage among their peers $(12,0 ; 20,-1)$.

In addition, Table 3 shows the Factor arrays which identifies how the Qsorts are configured to represent the viewpoints of the study Factors.

\section{DISCUSSION}

This study was able to identify distinct viewpoints held by HCPs based on their adoption and use of eHealth within their respective clinical practices. With the identification of these four Factors, HCPs in this study provided a holistic view of the equivocal influence eHealth interaction manifests amongst them.

\section{The patients' preference}


332 Factor 1 shows a positive relationship between the HCPs choice to adopt and use eHealth and

333

334

335

336

337

338

339

340

341

342

343

344

345

346

347

348

349

350

351

352

353

354

355

356

357

358

359

360

361

362

363

364

365

366

367

368

369

370

371

patient/families' attitudes and preferences towards its use during care. Ruland \& Bakken (2001) examined patient preference-related concepts for inclusion in electronic health records (EHR), and identified that the HCPs integration of patient preferences in clinical decisions are important 'pieces of evidence' for appropriate decision making (p415). However, like the studies of AlJafar (2013) and Koivunen et al. (2008), Factor 3 showed that patients (and families) preferences are not considered to inform choices of HCPs clinical practice. This Factor believe that their patients interaction with ICT and the internet will have less effect on their clinical outcome which is similar to HCPs characterised by Lupiáñez-Villanueva et al. (2011) as non-integrated. This shows the varying perspectives of both Factor 1 and Factor 3 on the HCPs using patient preference to inform their clinical practice. Thus, the integration of patient preferences in patient care (Ruland \& Bakken 2001) drives Factor 1 choices to adoption and use of eHealth in clinical practice. On the other hand, Factors 2 and 4 are both neutral on patient preferences informing their choices to eHealth use while showing emphasis on other determinants to their views on eHealth in clinical practice. This reflects the equivocal views on patient preference and eHealth adoption and use by HCPs.

\section{Task completion}

Another view uncovered by the study relates to Factor 2 which envisioned HCPs that are driven by the contribution of the eHealth into the completion of their clinical tasks. Unlike Factors 1, 3 and 4 the driving influence on the adoption and use of these eHealth resources is the ability of the technology to aid in completing tasks effectively and efficiently. Factor 2 are more concerned with getting through with their routines and the eHealth available provides them with the opportunity to do so. This resonates with some of the findings of Hains et al. (2009) who focused on a clinical decision support system. Hains et al. (2009) explored nurses and physicians use of a computerised clinical decision support system (Cancer Institute Standard Cancer Treatment Program: CI-SCaT). They identified among other findings, that some senior nurses and senior physicians utilise the eHealth resource because of convenience and its ability to consolidate the information that they may need. Participants within their study indicated that the availability of the resource and its ease of use motivates them to use it to accomplish their respective clinical task. Thus, driven by the need to carryout various clinical duties within a specific timeframe, HCPs in Factor 2 adopt these resources because using such technologies provides convenience and ease to their clinical task. Gough et al. (2014) also reported how nurses interact with new technologies. Though they only focused on nurses and non-specific digital clinical technology and information technologies, 125 participants were recruited across two Australian states in a qualitative research. They conducted interviews from five hospitals in the two states. Their findings indicated that nurses use these technologies because it makes their completion of tasks faster, easier and offers them more work. This showed that the HCPs in their study are more oriented towards their operational tasks only to support their practice. LupiáñezVillanueva et al. (2011) while examining the integration of ICT into nursing clinical practice identified a category of nurses that are similar to Factor 2 . They referred to this category as part 
372 of the 'non-integrated' HCPs: who were reported to 'use ICT and the internet in a restricted

373 fashion and only to directly support their nursing practice' ( $\mathrm{p} 138$ ). Thus, the choice to use

374 eHealth is influenced by how it can be consolidated towards their task completion.

375 Resistance and unintended consequences

376 On the other hand, Factor 3 shows a HCP that is more grounded in their day-to-day routine of

377 clinical duties without the utilisation of eHealth resources. Participants in Factor 3 shows that

378 they do not see the eHealth as part of their routine activities but rather as a conflicting task that

379 could not be combined with their normal schedules. Like in the study by Hains et al, even though

380 most HCPs highlighted the benefits of using the CI-SCaT, senior physicians emphasised that

381 they cannot be compelled to use the eHealth resource. Their findings identified that the senior

382 physicians cited issues of clinical autonomy as reason for non-adoption of these technologies.

383 However, professional roles (senior staff/junior staff; nurse/physician) have been identified to

384 have influence on clinical autonomy in relation to patient care (Verhoeven et al. 2009). Issues of

385 clinical autonomy (Brewster et al. 2014; Verhoeven et al. 2009) and resistance to technology

386 (Doolin 2004; Greenhalgh et al. 2014; Timmons 2003) play an important part in determining

387 how HCPs interpret how eHealth modify their interactions with the patients.

388 While describing issues of both resistance and clinical autonomy, Verhoeven et al. (2009)

389 explored factors affecting healthcare workers adoption of an online resource for infection

390 control. They identified that senior physicians reported that they have the necessary skills and

391 training and will therefore not engage with the resource provided. This indicates that the senior

392 physicians have similar views in the study by Hains et al. (2009) as mentioned above. Thus, the

393 consequence of the availability of both eHealth resources in the aforementioned studies and in

394 the present study shows that senior physicians drive the issue of clinical autonomy to avoid

395 adoption of eHealth resources. This was also seen in this study as seen in the comment by one of

396 the participants:

397 “..., there were moments when the IT (information technology) was introduced but some certain

398 individuals [senior physicians] actually resist it. Feeling that because it is not understandable,

399 it's not clear to them as in complicates their work that is the task that is been given to them. So

400 they prefer to adopting (sic) the manual way rather than going the ICT way. But for most of them

401 it's because it's not clear to them actually" (P3)

402 Though other researchers such as Gosling, 2004 cited in Gerrish et al. (2006) reported a contrary

403 view to the one cited above. He identified that senior nurses were shown to utilise information

404 technologies more than their junior colleagues. HCPs in Factor 3 are comfortable by doing what

405 they have routinely been doing without integrating the eHealth in their daily clinical activities.

406 The already busy setting of the clinical area hinders the adoption of eHealth as suggested by

407 Bossen (2007) because of the recursive nature of these technologies, eHealth use is seen by them

408 as an extra task and thus avoided. In addition, Brewster et al. (2014) review of factors affecting

409 frontline staff acceptance of health technologies reported that nurses often view eHealth as extra

410 responsibility and not a part of routine healthcare practice. Verhoeven et al. (2009) adds to this 
411 by arguing that the already existing stress at the work place and poor understanding of how

412 eHealth resources work, these HCPs get "put off" from adopting and using them.

413 Resistance to healthcare technologies has also been identified to influence adoption and use of

414 information technologies in clinical practice (Bacon \& Stocking 2004; Doolin 2004; Doolin

415 2016; Greenhalgh et al. 2014; Timmons 2003). HCPs avoid using the eHealth because they do

416 not understand how the technologies work or use it for non-clinical activity. In this regard,

417 Timmons argues that what may constitute as "resistance" may vary when describing HCPs

418 resistance to information technology. This could range from refusal to use the information

419 system to criticism of the available technology (Timmons 2003) or if using the eHealth is seen as

420 extra work (Eley et al. 2009). In the same way, resistance to eHealth could be viewed as a

421 message to those in power (Doolin 2004) or the hospital management to express dissatisfaction

422 with imposition of eHealth on the HCPs due to non-end-user consultation prior to

423 implementation. This manifests in what Timmons (2003) and Geiger et al. (2017) refer to as

424 resistive compliance and supportive non-use respectively. Evidently there were a lot of concerns

425 by HCPs across all the four Factors about management attitude in the provision of the eHealth

426 resources in the study area.

427 Thus the manifestation of non-use of eHealth by Factor 3 and the consensus by all the Factors

428 about not getting their superiors' support to adopting and using these technologies would be an

429 'unintended consequence' (Harrison et al. 2007) of these eHealth resources (Lupiáñez-

430 Villanueva et al. 2011). These unintended/unanticipated changes to routine HCPs in terms of

431 eHealth adoption and use is what Massaro (1993) cited in Timmons (2003) summed up to be

432 within the locus of resistance. This type of resistance by HCPs was reported by Massaro to be

433 because of complex and emotional views which could be interpreted as contradictory positions

434 on ICT in clinical practice.

435 It is worth acknowledging that though some of the literature which discussed resistance might be

436 adjudged to be not so recent, their relevance within this discourse has been cited to be important

437 by more recent researchers (Gagnon et al. 2012).

\section{Integrating eHealth in daily clinical duties}

439 Factor 4 suggested a HCP that always engages in adopting and using the eHealth. Similar to the

440 e-advocates nurse lecturers in Petit dit Dariel et al. (2013) Q-study on e-learning, this group of

441 HCPs see eHealth as a tool that could improve both the quality of patient care and the potential

442 to use it beyond their clinical departments. Also Hains et al. (2009) showed that nurses and

443 junior doctors within their study exhibited similar views about the eHealth (CI-SCaT) akin to

444 HCPs in this study. Though both the two studies mentioned used different (e-learning and CI-

$445 \mathrm{SCaT}$ ) technologies both HCPs including those in Factor 4 demonstrated that these technologies

446 play important roles in their clinical practices. Hains et al. (2009) reports that participants in their

447 study praised both the quality and structure of the eHealth tool identifying it as part of their

448 routine clinical tasks unlike Factor 3. Hier et al. (2004) findings on acceptance of EHR, reported

449 that both groups of participants (senior and junior physicians) within their study showed more

450 than $88 \%$ positive attitudes towards using EHR in their clinical practice even though the 
451 acceptance was reported higher for the junior physicians. Also, Joos et al. (2006) explored 452 electronic medical record use in primary care. Their findings indicated that physicians identified 453 efficiency gains on using electronic medical records (EMR) resources and also reported the need 454 to use it beyond their respective clinical environment. These participants like in Factor 4 455 generally agreed that the use of the eHealth resources improved their clinical practice.

456 Factor 4 also resonates with the first profile categorisation of HCPs (nurses) by Lupiáñez457 Villanueva et al. (2011). The authors described the HCPs as 'integrated nurses', who by their 458 characterisation place high emphasis on eHealth so much so that it forms an important aspect of 459 their clinical practice (Lupiáñez-Villanueva et al. 2011). This shows how those who contribute to 460 Factor 4 champion the use of these eHealth resources and advocate its use beyond their

461

462

463

464

465

466

467

468

469

470

471

472

473

474

475

476

477

478

479

480

481

482

483

484

485

486

487

488

489 departments and drawing on the similarity to Lupiáñez-Villanueva et al. (2011), these HCPs are predicted to be involved in research activities. Factor 4 represents HCPs who see eHealth from an unrestricted broader application within clinical practice unlike Factor 2.

Despite the contrasting viewpoints across the four Factors, they all acknowledge that eHealth has an important role to play in improving quality healthcare. This is similar to the findings of Zayyad \& Toycan (2018) who identified that HCPs in their recognise the roles that eHealth in provision of care. In addition, HCPs in this study also recognise that they get poor support from their superiors in terms of using eHealth resources within their clinical practice. In addition to what all the four Factors have a consensus on is the issue that both gender and age has no influence on their adoption of these eHealth resources as reported by Kaouri et al 2005 cited in Gagnon et al. (2012).

This study has shown that though eHealth is recognised as a component of healthcare practice by the Ministry of Health in Nigeria, a substantive policy guiding development, implementation and evaluation is not well defined. Hence this study identified that HCPs are not bound to eHealth adoption policies within their clinical work environment. This has resulted in healthcare institutions having local policies that are usually not sustainable as most key stakeholders are not involved. Findings from this study has also shown that even within various departments within the same institution eHealth policies exist without collaboration with other departments but rather with organisations outside these institutions. In the UK, there is a routine eHealth policy update (Burns 1998; Robert 2016) which sets strategies for implementation and evaluates previous policies to match with healthcare evolving needs. This study may empower policy makers in SSA to recognise the different perspectives that HCPs have about eHealth adoption and use in clinical practice. In addition, areas of concern such as involving HCPs in decision making through feedback about the appropriate eHealth to be implemented should be encouraged. Monitoring of adoption could also be done by keeping an audit trail of use to address compliance and areas of concern. Patient preference should also be taken into consideration while developing such policies since this study has shown these preferences influence HCPs eHealth adoption and use choices. 
490 This study uncovered distinct viewpoints that participants identified as factors influencing their 491 adoption and use of eHealth in their clinical practice. Using Qmethodology HCPs were able to 492 rank-order statements drawn from the issues concerning their interaction with eHealth in their 493 practice, which was subsequently viewed in a holistic way. Salient issues such as the unintended 494 consequences of eHealth, and how patients' preferences play important roles influencing HCPs choices to adopt and use eHealth were revealed by these participants. Therefore, findings will help guide policymakers and decision makers within eHealth to be aware of the divergent preferences that HCPs might have towards eHealth resources in clinical practice. In addition, issues such as involving the consumers of these eHealth resources i.e. HCPs when making choices about the type of eHealth tool to be provided to them should always be taken into consideration when deciding on eHealth implementation.

As a limitation, indeed findings of this study are not generalisable beyond the participants due to their small number. However, the concepts that emerged might be transferable to other HCPs in other similar settings due to the variant perspectives generated (Thomas \& Baas 1992; Watts \& Stenner 2012). In this regard, future research could employ quantitative techniques to examine the viewpoints that emerge within this study among a larger population of HCPs. Models on the a tripartite relationship between eHealth, HCPs and their patients relationship could be developed from the findings and examined to identify the strengths or weaknesses of such interactions.

\section{ACKNOWLEDGEMENTS}

The authors with to acknowledge the T\&Q community UK, the Qmethodology listserv for their valuable feedback during the analysis stage.

\section{REFERENCES}

ABUTH. 2017. About Ahmadu Bello University Teaching Hospital. Available at http://abuth.org.ng/index.php/about-abuth (accessed 4/1/2017 2017).

Akanbi MO, Ocheke AN, Agaba PA, Daniyam CA, Agaba El, Okeke EN, and Ukoli CO. 2012. Use of Electronic Health Records in sub-Saharan Africa: Progress and challenges. Journal of medicine in the tropics 14:1-6.

Akhtar-Danesh N, Baumann A, and Cordingley L. 2008. Q-methodology in nursing research: a promising method for the study of subjectivity. West J Nurs Res 30:759-773. 10.1177/0193945907312979

Al-Jafar E. 2013. Exploring Patient Satisfaction Before and After Electronic Health Record (EHR) Implementation: The Kuwait Experience. Perspectives in Health Information Management / AHIMA, American Health Information Management Association 10:1c.

Ami-Narh JT, and Williams PAH. 2012. A revised UTAUT model to investigate E-health acceptance of health professionals in africa. Journal of Emerging Trends in Computing and Information Sciences 3:1383-1391.

Bacon F, and Stocking S. 2004. The role of gender in the outcome of ICT adoption - can nurses be technologists? Human Perspectives in the Internet Society: Culture, Psychology and Gender 31:183-190.

Barello S, Triberti S, Graffigna G, Libreri C, Serino S, Hibbard J, and Riva G. 2015. eHealth for Patient Engagement: A Systematic Review. Frontiers in Psychology 6:2013. 10.3389/fpsyg.2015.02013 
533

534

535

536

537

538

539

540

541

542

543

544

545

546

547

548

549

550

551

552

553

554

555

556

557

558

559

560

561

562

563

564

565

566

567

568

569

570

571

572

573

574

575

576

577

578

579

580

581

582

583

Bossen C. 2007. Test the artefact-Develop the organization. International Journal of Medical Informatics 76:13-21. http://dx.doi.org/10.1016/j.ijmedinf.2006.01.001

Brewster L, Mountain G, Wessels B, Kelly C, and Hawley M. 2014. Factors affecting front line staff acceptance of telehealth technologies: a mixed-method systematic review. J Adv Nurs 70:21-33. 10.1111/jan.12196

Brown S. 2010. Re: Number of participants. In: <Q-METHOD@LISTSERV.KENT.EDU> QMN, editor. https://listserv.kent.edu/cgi-bin/wa.exe?A2=ind1002\&L=qmethod\&P=R15714\&1=qmethod\&9=A\&J=on\&X=82A4EDB9E297C9976B\&Y=ntxmal\%40nottingham.ac.uk\&d=No +Match\%3BMatch\%3BMatches\&z=4.

Brown SR. 1980. Political Subjectivity: APPLICATIONS OF Q METHODOLOGY IN POLITICAL SCIENCE. United States of America: Yale University.

Buntin MB, Burke MF, Hoaglin MC, and Blumenthal D. 2011. The Benefits Of Health Information Technology: A Review Of The Recent Literature Shows Predominantly Positive Results. Health Affairs 30:464-471. 10.1377/hlthaff.2011.0178

Burns F. 1998. Information for Health: An Information Strategy for the Modern NHS 1998-2005 a National Stragy for Local Implementation. In: Publications DoH, editor. United Kingdom: Department of Health Publications.

Doolin B. 2004. Power and resistance in the implementation of a medical management information system. Information Systems Journal 14:343-362. 10.1111/j.13652575.2004.00176.x

Doolin B. 2016. The Oxford handbook of health care management / edited by Ewan Ferlie, Kathleen Montgomery, and Anne Reff Pedersen. In: Ferlie E, Montgomery K, and Reff Pedersen A, eds. Handbook of health care management. 2016 ed. Oxford: Oxford : Oxford University Press, 352-374.

Eley R, Fallon T, Soar J, Buikstra E, and Hegney D. 2009. Barriers to use of information and computer technology by Australia's nurses: a national survey. Journal of Clinical Nursing 18:1151-1158. 10.1111/j.1365-2702.2008.02336.x

Gagnon M-P, Nsangou É-R, Payne-Gagnon J, Grenier S, and Sicotte C. 2014. Barriers and facilitators to implementing electronic prescription: a systematic review of user groups' perceptions. Journal of the American Medical Informatics Association 21:535-541.

Gagnon MP, Desmartis M, Labrecque M, Car J, Pagliari C, Pluye P, Fremont P, Gagnon J, Tremblay N, and Legare F. 2012. Systematic review of factors influencing the adoption of information and communication technologies by healthcare professionals. J Med Syst 36:241-277. 10.1007/s10916-010-9473-4

Geiger M, Waizenegger L, Treasure-Jones T, Sarigianni C, and Maier R. 2017. NOT JUST ANOTHER TYPE OF RESISTANCE - TOWARDS A DEEPER UNDERSTANDING OF SUPPORTIVE NONUSE. Association for Information Systems: AIS Electronic Library June 2017:2366-2381.

Gerrish K, Morgan L, Mabbott I, Debbage S, Entwistle B, Ireland M, Taylor C, and Warnock C. 2006. Factors influencing use of information technology by nurses and midwives. Practice Development in Health Care 5:92-101. 10.1002/pdh.184

Gough R, Ballardie R, and Brewer P. 2014. New technology and nurses. Labour \& Industry: a journal of the social and economic relations of work 24:9-25. 10.1080/10301763.2013.877118

Greenhalgh T, Swinglehurst D, and Stones R. 2014. Rethinking resistance to 'big IT': a sociological study of why and when healthcare staff do not use nationally mandated information and communication technologies. HEALTH SERVICES AND DELIVERY RESEARCH 2:1-86. 10.3310/hsdr02390

Hains IM, Fuller JM, Ward RL, and Pearson S-A. 2009. Standardizing care in medical oncology. Cancer 115:5579-5588. 10.1002/cncr.24600 
584

585

586

587

588

589

590

591

592

593

594

595

596

597

598

599

600

601

602

603

604

605

606

607

608

609

610

611

612

613

614

615

616

617

618

619

620

621

622

623

624

625

626

627

628

629

630

631

632

633

Harrison MI, Koppel R, and Bar-Lev S. 2007. Unintended Consequences of Information Technologies in Health Care-An Interactive Sociotechnical Analysis. Journal of the American Medical Informatics Association : JAMIA 14:542-549. 10.1197/jamia.M2384

Hier DB, Rothschild A Fau - LeMaistre A, LeMaistre A Fau - Keeler J, and Keeler J. 2004. Differing faculty and housestaff acceptance of an electronic health record one year after implementation. Stud Health Technol Inform 107:1300-1303.

Ho GWK. 2017. Examining Perceptions and Attitudes: A Review of Likert-Type Scales Versus Q-Methodology. Western Journal of Nursing Research 39:674-689. $10.1177 / 0193945916661302$

Joos D, Chen Q, Jirjis J, and Johnson KB. 2006. An Electronic Medical Record in Primary Care: Impact on Satisfaction, Work Efficiency and Clinic Processes. AMIA Annual Symposium Proceedings 2006:394-398.

Koivunen M, Hätönen $\mathrm{H}$, and Välimäki M. 2008. Barriers and facilitators influencing the implementation of an interactive Internet-portal application for patient education in psychiatric hospitals. Patient Education and Counseling 70:412-419. http://dx.doi.org/10.1016/j.pec.2007.11.002

Ladan MA, Wharrad H, and Windle R. 2018. Towards understanding healthcare professionals' adoption and use of technologies in clinical practice: Using Qmethodology and models of technology acceptance. Journal of Innovation in Health Informatics 25:27-37. 10.14236/jhi.v25i1.965

Lupiáñez-Villanueva F, Hardey M, Torrent J, and Ficapal P. 2011. The integration of Information and Communication Technology into nursing. International Journal of Medical Informatics 80:133-140. http://dx.doi.org/10.1016/j.jijmedinf.2010.11.001

Paige JB, and Morin KH. 2015. Using Q-Methodology to Reveal Nurse Educators' Perspectives about Simulation Design. Clinical Simulation in Nursing 11:11-19. http://dx.doi.org/10.1016/j.ecns.2014.09.010

Petit dit Dariel O, Wharrad H, and Windle R. 2013. Exploring the underlying factors influencing e-learning adoption in nurse education. J Adv Nurs 69:1289-1300. 10.1111/j.13652648.2012.06120.x

Phichitchaisopa N, and Naenna T. 2013. FACTORS AFFECTING THE ADOPTION OF HEALTHCARE INFORMATION TECHNOLOGY. Excli Journal 12:413-436.

Ramlo S. 2015. Mixed Method Lessons Learned From 80 Years of Q Methodology. Journal of Mixed Methods Research.

Ramlo SE, and Newman I. 2011. Q Methodology and Its Position in the Mixed-Methods Continuum. Operant Subjectivity: The International Journal of Q Methodology 34:172191.

RCN. 2017. eHealth. Available at https://www.rcn.org.uk/clinical-topics/ehealth (accessed 5/06/2017 2017).

Robert MW. 2016. Making IT Work: Harnessing the Power of Health information Technology to Improve Care in England. In: Lea W, editor. UK: National Advisory Group on Health Information Technology in England. $p 6$.

Ruland CM, and Bakken S. 2001. Representing Patient Preference-Related Concepts for Inclusion in Electronic Health Records. Journal of Biomedical Informatics 34:415-422. http://dx.doi.org/10.1006/jbin.2002.1035

Schmolck P. 2014. PQMethod Download Page for Windows Users. Available at http://schmolck.userweb.mwn.de/qmethod/downpqwin.htm (accessed Janaury 2017).

Stenner P. 2009. Q methodology as a constructivist methodology. Operant Subjectivity 32:1-32.

Stenner PHD, Dancey CP, and Watts S. 2000. The understanding of their illness amongst people with irritable bowel syndrome: a Q methodological study. Social Science \& Medicine 51:439-452. http://dx.doi.org/10.1016/S0277-9536(99)00475-X 
634

635

636

637

638

639

640

641

642

643

644

645

646

647

648

649

650

651

652

653

654

655

656

657

658

659

660

661

662

Stephenson W. 1986. PROTOCONCURSUS: THE CONCOURSE THEORY OF COMMUNICATION. Operant Subjectivity 9:37-58.

Terry AL, Giles G, Brown JB, Thind A, and Stewart M. 2009. Adoption of Electronic Medical Records in Family Practice: The Providers' Perspective. Family Medicine 41:508-512.

Thomas DB, and Baas LR. 1992. The Issue of Generalization in Q Methodology: "Reliable Schematics" Revisited. Operant Subjectivity 16:18-36. 10.15133/j.os.1992.014

Timmons S. 2003. Nurses resisting information technology. Nursing Inquiry 10:257-269. 10.1046/j.1440-1800.2003.00177.x

vanExel J, and Graaf Gd. 2005. Q methodology: A sneak preview. p 1-21.

Venkatesh V, and Bala H. 2008. Technology Acceptance Model 3 and a Research Agenda on Interventions. Decision Sciences 39:273-315. 10.1111/j.1540-5915.2008.00192.x

Verhoeven F, Steehouder MF, Hendrix RMG, and van Gemert-Pijnen JEWC. 2009. Factors affecting health care workers' adoption of a website with infection control guidelines. International Journal of Medical Informatics 78:663-678. http://dx.doi.org/10.1016/j.ijmedinf.2009.06.001

Watts S, Hughes M, and Lewis J. 2018. Using Q Methodology as a Course Feedback System. 55 City Road, London.

Watts S, and Stenner P. 2005. Qualitative Research in Psychology. England and Wales: Routledge. p 67-91.

Watts S, and Stenner P. 2012. Doing Methodological Research: Theory, Method and Interpretation. London: SAGE.

Webler T, Danielson S, and Tuler S. 2009. Using Q Method to Reveal Social Perspectives in Environmental Research. Greenfield MA: Social and Environmental Research Institute.

Zabala A, and Pascual U. 2016. Bootstrapping Q Methodology to Improve the Understanding of Human Perspectives. PLoS One 11:e0148087. 10.1371/journal.pone.0148087

Zayyad MA, and Toycan M. 2018. Factors affecting sustainable adoption of e-health technology in developing countries: an exploratory survey of Nigerian hospitals from the perspective of healthcare professionals. PeerJ 6:e4436. 10.7717/peerj.4436 


\section{Table $\mathbf{1}$ (on next page)}

P-matrix showing participants' characteristics

This matrix resulted in yielded a possible combination of 2 [Gender] $\times 3$ [Age] $\times 3$ [Years of Experience] $\times 2$ [Profession] and making a total of thirty-six P-set. It is important to note the participants in Q-methodology are not selected at random but rather purposively based on the characteristics they possess that make them relevant to the context of the study (Bartlett \& DeWeese, 2015; vanExel \& Graaf, 2005). 
1 P-matrix showing participants' characteristics

\begin{tabular}{|llll|}
\hline a. Gender & Male & Female & \\
b. Age & $<35$ years & $35-45$ years & $>45$ years \\
c. Years of & $<3$ years & $3-7$ years & $>7$ years \\
experience & & & \\
d. Profession & Nurse & Physician & \\
\hline
\end{tabular}

2 
Table 2 (on next page)

Socio-demographic characteristics of participants 
1 Socio-demographic characteristics of participants

\begin{tabular}{|clc|}
\hline Gender & Frequency & Percent (\%) \\
Male & & 52.8 \\
Female & 19 & 47.2 \\
Age (years) & 17 & \\
$<\mathbf{3 5}$ & & 19.4 \\
$\mathbf{3 5 - 4 5}$ & 7 & 47.2 \\
$\mathbf{> 4 5}$ & 17 & 33.3 \\
Profession & 12 & 50 \\
Nurse & & 50 \\
Physician & 18 & \\
\hline
\end{tabular}

2 


\section{Table 3 (on next page)}

Factor Arrays showing statement ranking across all Factors 


\section{Factor Arrays showing statement ranking across all Factors}

\begin{tabular}{|c|c|c|c|c|c|}
\hline \multirow[t]{2}{*}{ No. } & \multirow[t]{2}{*}{ Statement } & \multicolumn{4}{|c|}{ Factors } \\
\hline & & F1 & F2 & F3 & F4 \\
\hline 1. & It is easy to remember how to perform tasks with the clinical information systems & 2 & 0 & 0 & 2 \\
\hline 2. & Using clinical information systems improves patient care & 4 & 5 & 1 & 3 \\
\hline 3. & Using clinical information systems reduces likelihood of medication error & 0 & 2 & -2 & 2 \\
\hline 4. & Superiors at work think I should use the clinical information systems & -1 & -2 & -2 & -2 \\
\hline 5. & If the clinical system is extended I would use it & 6 & 1 & 2 & 1 \\
\hline 6. & Using clinical information systems increases my productivity & 2 & 4 & 4 & 1 \\
\hline 7. & Using clinical information systems improves my performance & 4 & 5 & 2 & 4 \\
\hline 8. & I am certain about the reliability of the information I get from the system & 1 & -3 & 3 & 1 \\
\hline 9. & Using clinical information systems facilitates better patient care decision making & 3 & 6 & 1 & 0 \\
\hline 10. & Using clinical information systems makes caring for patients easier & 4 & 3 & 1 & 3 \\
\hline 11. & $\begin{array}{l}\text { Management support staff innovations on clinical information systems use in the } \\
\text { workplace }\end{array}$ & -5 & -4 & -1 & -4 \\
\hline 12. & $\begin{array}{l}\text { People in my organization who use the clinical information systems have more } \\
\text { prestige than those who do not }\end{array}$ & -2 & -4 & -5 & 0 \\
\hline 13. & The use of clinical information systems makes me apprehensive & -4 & -5 & -1 & -3 \\
\hline 14. & Using the clinical information systems is a status symbol in my organization & -3 & -6 & 0 & -1 \\
\hline 15. & $\begin{array}{l}\text { Patients/families believe clinical information systems use reduces chances of } \\
\text { medication errors }\end{array}$ & 2 & 0 & -5 & -1 \\
\hline 16. & It is easy to get the system to do what I want it to do & -2 & 0 & 1 & 3 \\
\hline 17. & Interaction with the clinical information systems does not require a lot of mental effort & -2 & -4 & -1 & 0 \\
\hline 18. & $\begin{array}{l}\text { Not having the clinical information system in some departments hinders my work in } \\
\text { these areas }\end{array}$ & 1 & -1 & -4 & 4 \\
\hline 19. & $\begin{array}{l}\text { The senior management of this organization has been helpful in the use of the clinical } \\
\text { information systems }\end{array}$ & -4 & 2 & -3 & -6 \\
\hline 20. & Using clinical information systems increases my chance of getting a praise or reward & -2 & -2 & -4 & -1 \\
\hline 21. & The use of clinical information systems is pertinent to my various related tasks & 0 & 1 & 0 & 2 \\
\hline 22. & The clinical information systems are clear and understandable & -3 & 3 & 0 & 2 \\
\hline 23. & My use of clinical information systems is entirely voluntary & 3 & 0 & 6 & 3 \\
\hline 24. & $\begin{array}{l}\text { My age has nothing to do with my ability to use the clinical information systems } \\
\text { effectively }\end{array}$ & 5 & 2 & 4 & 0 \\
\hline 25. & My use of clinical information systems is entirely under my control & -3 & -2 & 2 & 0 \\
\hline 26. & It is easy for me to become skilful at using clinical information systems & 1 & 3 & 3 & 4 \\
\hline 27. & I always look for opportunities to use the system whenever I can & 3 & 1 & 3 & 5 \\
\hline 28. & $\begin{array}{l}\text { Management organise regular training on the use of clinical information systems at } \\
\text { the work place }\end{array}$ & -6 & -3 & -3 & -5 \\
\hline 29. & Clinical Information systems are useful in the hospital & 5 & 5 & 5 & 6 \\
\hline 30. & My routine tasks prevent me from having time to use the clinical information system & -1 & -3 & 5 & -3 \\
\hline 31. & $\begin{array}{l}\text { I could complete the job using the clinical information systems if there was no one } \\
\text { around to tell me what to do as I go }\end{array}$ & 0 & 0 & 3 & 1 \\
\hline 32. & $\begin{array}{l}\text { There is availability of technical assistance for clinical information systems in my } \\
\text { hospital }\end{array}$ & -5 & -1 & -1 & -5 \\
\hline 33. & Clinical information systems improve work efficiency & 5 & 4 & 4 & 5 \\
\hline 34. & Using clinical information systems is easier than other computer systems I use & -1 & -1 & 2 & -2 \\
\hline 35. & Patients/families like it when I uses the clinical information system & 1 & -1 & -5 & -3 \\
\hline 36. & My ICT experience affects my use of the clinical information system & -1 & 3 & 0 & 0 \\
\hline 37. & People who influence my clinical behaviour think I should the system & 2 & 0 & 0 & -2 \\
\hline 38. & There are available resources to use the clinical information system & -4 & 1 & -2 & -4 \\
\hline 39. & Using clinical information systems enables me to accomplish tasks more quickly & 3 & 4 & 5 & 5 \\
\hline 40. & My gender affects my use of the clinical information systems & -5 & -5 & -6 & -5 \\
\hline 41. & People who are important to me think I should use the clinical information systems & 0 & -1 & 1 & -2 \\
\hline
\end{tabular}


42. Patients/families believe clinical information systems use is good for quality patient $\quad \begin{array}{llll}0 & 1 & -3 & -1\end{array}$ care

43. I hesitate to use the clinical information systems for fear of making mistakes I cannot $\quad \begin{array}{lllll}0 & -5 & -1 & -3\end{array}$ correct

44. The information in the system is always updated

$\begin{array}{llll}-3 & -2 & -4 & 1\end{array}$

45. My use of the clinical information system is specific to the task i want to carry out

46. The clinical information systems is not compatible with other platforms I use

$\begin{array}{lllll}1 & 2 & -2 & -1\end{array}$

2 
Table 4 (on next page)

Viewpoints (Factors) of HCPs on eHealth adoption and use 
1 Viewpoints (Factors) of HCPs on eHealth adoption and use

\begin{tabular}{|l|l|l|}
\hline Factor 1 & $\begin{array}{l}\text { Patient-focused } \\
\text { eHealth advocates }\end{array}$ & $\begin{array}{l}\text { HCPs use the eHealth resources because they } \\
\text { are motivated by the patients and their families. }\end{array}$ \\
\hline Factor 2 & $\begin{array}{l}\text { Task-focused eHealth } \\
\text { advocates }\end{array}$ & $\begin{array}{l}\text { HCPs use the eHealth because it helps them } \\
\text { accomplish their clinical tasks }\end{array}$ \\
\hline Factor 3 & $\begin{array}{l}\text { Traditionalistic- } \\
\text { pragmatists }\end{array}$ & $\begin{array}{l}\text { HCPs recognise the contributions eHealth } \\
\text { makes in clinical practice, but they see it } \\
\text { separate from their routine clinical activities }\end{array}$ \\
\hline Factor 4 & $\begin{array}{l}\text { Tech-focused eHealth } \\
\text { advocates }\end{array}$ & $\begin{array}{l}\text { HCPs the eHealth resources because they are } \\
\text { motivated by the technology itself }\end{array}$ \\
\hline
\end{tabular}

2 


\section{Figure 1 (on next page)}

Sorting grid 
Most Disagree

$-6 \quad-5$

$-4$

$-3$

$-2$

$-1$

0

$+1$

$+2$

$+3$

$+4$

Most Agree

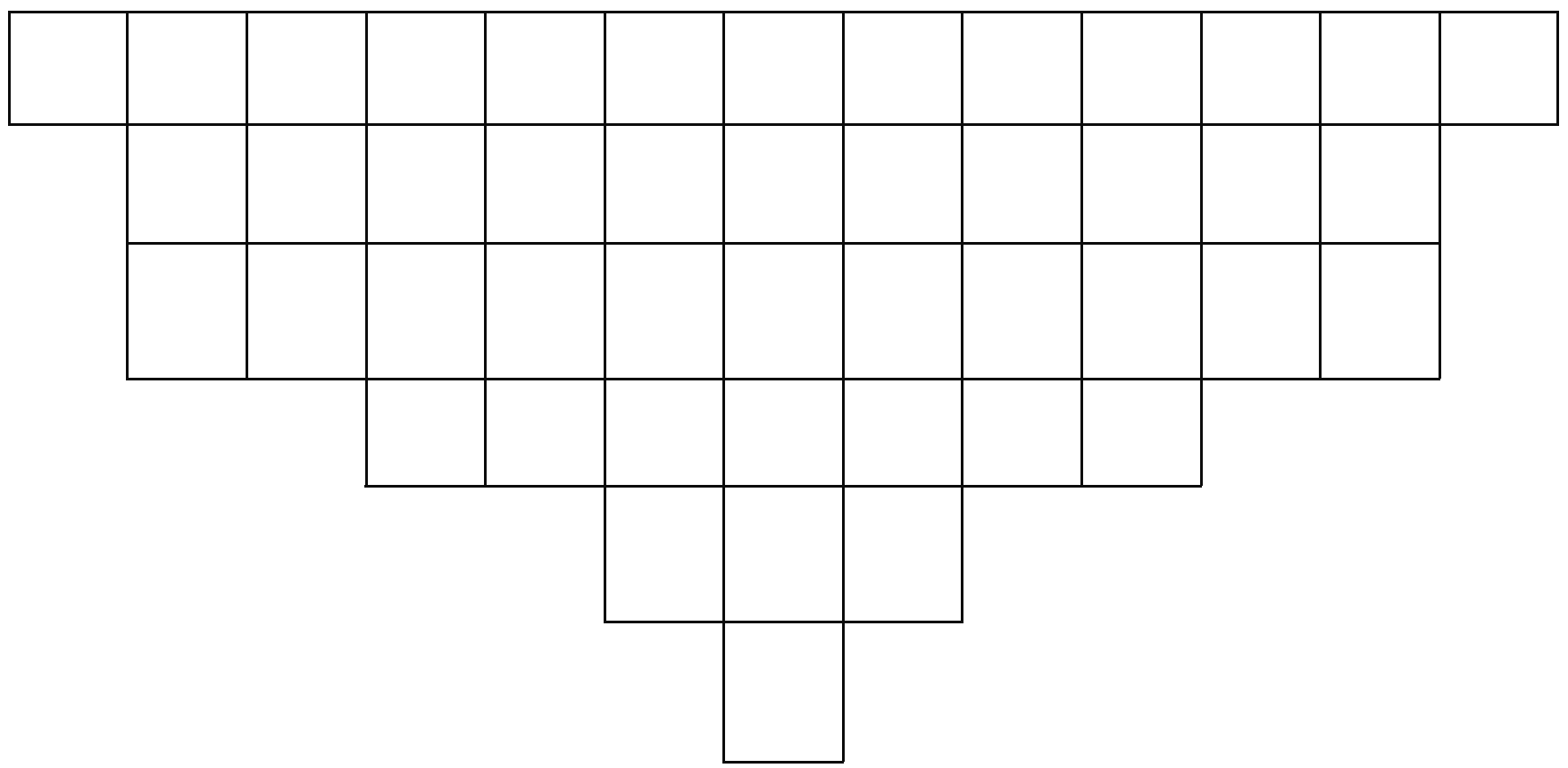

